\title{
Aplicaciones de las técnicas de neuroimagen en las conductas adictivas
}

\author{
Guardia Serecigni, J.; Segura García, L.; Gonzalbo Cirac, B. \\ Unidad de Conductas Adictivas. Servicio de Psiquiatría. Hospital de la Santa Creu i Sant Pau \\ Enviar correspondencia a: \\ Hospital de la Santa Creu i Sant Pau. C/ San Antonio Ma Claret, 165. 08025 BARCELONA \\ Tel. 93 291.91.31. Fax 93 291.91.78. E-mail: 4204@hsp.santpau.es
}

\section{RESUMEN}

Las técnicas de neuroimagen facilitan tanto el estudio funcional y estructural del cerebro, como la evaluación de los efectos que sobre el mismo producen los psicofármacos y las sustancias psicoactivas.

Las técnicas de imagen estructural, como la tomografía cerebral y la resonancia magnética estructural, han sido utilizadas para detectar cambios en el volumen tisular de la sustancia gris y blanca, tras el consumo excesivo y prolongado de alcohol, su relación con el envejecimiento y su reversibilidad con la abstinencia continuada.

Las técnicas de imagen funcional (PET, SPECT, resonancia magnética funcional y espectroscópica), permiten relacionar la actividad de algunas regiones del cerebro con la conducta. Mediante la utilización de radiofármacos, o drogas marcadas con isótopos radiactivos, se puede obtener información sobre las alteraciones funcionales de la neurotransmisión, que subyacen a determinados fenómenos como el efecto reforzador, el "craving", la tolerancia al alcohol, la abstinencia, etc.

Las nuevas técnicas de neuroimagen podrían aportar un mayor conocimiento sobre los circuítos neuro-anatómicos y neuro-químicos, que modulan los efectos emocionales, cognitivos, motivacionales y reforzadores de las sustancias psicotrópicas. Todo ello podría resultar decisivo para el desarrollo de las neurociencias y también de una nueva farmacoterapia para las conductas adictivas.

Palabras clave: Técnicas de neuroimagen, conductas adictivas, alcoholismo, resonancia magnética cerebral, tomografía por emisión de positrones (PET), tomografía por emisión de fotón simple (SPECT).

\section{SUMMARY}

Neuroimaging methodologies allow functional and structural study of the brain, such as evaluation of the effects of psychiatric drugs and substances of abuse.

Structural image methodologies, such as cerebral tomography or structural magnetic resonance have been used to detect changes in the volume of gray and white substance after heavy and chronic alcohol consumption, and also to study these changes in relation to the aging process and their reversibility with continued abstinence of alcohol.

Functional image methodologies, like PET, SPECT, functional and spectroscopic magnetic resonance, can establish relationships between the activity of some brain regions and behavior. Information about some neurotransmission functional disorders, underlying phenomena like craving, reinforcing effects, tolerance to alcohol or withdrawal, can be obtained, using radiotracers or radioactive marked drugs.

The new neuroimaging techniques can provide greater knowledge of the neuro-anatomy and neuro-chemistry underlying the emotional, cognitive, motivational and reinforcing effects of psychotropic drugs. This could play an important role in the development of neurosciences and the pharmacotherapy of addictive behaviors

Key words: Neuroimaging methodologies, addictive behaviors, alcoholism, brain magnetic resonance, positron emission tomography (PET), single photon emission computerized tomography (SPECT).

\section{INTRODUCCIÓN}

as técnicas de imagen cerebral permiten el estudio del cerebro humano en vivo. Los procedimientos originarios, como la arteriografía carotídea y la neumoencefalografía eran complicadas y no exentas de riesgo. La neumoencefalografía se practicaba mediante la sustitución del líquido cefalorraquí- deo (LCR) por la inyección de aire, al interior de los ventrículos cerebrales y permitía visualizar las cavidades normalmente bañadas por dicho fluído corporal.

Las actuales técnicas de neuroimagen se clasifican en estructurales y funcionales. Las técnicas estructurales son la Tomografía computarizda (TC) y la Resonancia magnética estructural (RME); mientras que las técnicas funcionales son la Tomografía por emisión de 
positrones (PET), Tomografía por emisión de fotón simple computarizada (SPECT), Resonancia magnética funcional (RMF) y Resonancia magnética espectroscópica (RMS).

Las técnicas de imagen funcional permiten medir simultáneamente la actividad funcional del cerebro y la conducta, lo cual puede ser una valiosa herramienta para comprender las estructuras cerebrales y las vías neuro-químicas que subyacen al "craving" y a la pérdida de control sobre la conducta compulsiva de autoadministración de drogas. En el futuro pueden contribuir al desarrollo de nuevas farmacoterapias para las drogodependencias, facilitando la comprensión de los circuítos neuro-anatómicos y neuro-químicos que controlan los efectos emocionales, cognitivos, motivacionales y reforzadores del consumo de sustancias psicotrópicas.

\subsection{TOMOGRAFÍA COMPUTARIZADA CERE- BRAL (TC)}

Permite detectar el aumento de tamaño de los ventrículos cerebrales (dilatación ventricular), así como también de los surcos y cisuras de la corteza cerebral. Signos indirectos de retracción del parénquima cerebral que se conoce con la denominación genérica de atrofia cerebral.

LaTC proporciona imágenes de cortes del cerebro, paralelos a la línea órbito-meatal, desde la base del cráneo hasta la convexidad de la corteza parieto-occipital. Para determinar los parámetros de la normalidad en población general, se han efectuado mediciones del ínidice bicaudado, índice biventricular, anchura del III ventrículo y estudio de los surcos corticales (número, tamaño y localización) (Guardia y cols., 1982).

La TC permite el reconocimiento de lesiones vasculares cerebrales y encefalopatías de etiología tóxica o por déficits vitamínicos, relacionadas con el consumo excesivo de alcohol. El uso de contrastes yodados permite, además, el diagnóstico de ciertos tumores, infecciones y enfermedades vasculares, pero tiene el riesgo de reacción anafiláctica, sobretodo en pacientes alérgicos o asmáticos (Kaplan, Sadock y Grebb, 1996).

El grado de atrofia cerebral es mayor en relación a la edad del paciente, pero no parece estar en relación con su grado de deterioro neuropsicológico, evaluado mediante la exploración psicométrica. Además, se ha comprobado que la intensidad de la atrofia cerebral disminuye tras el tratamiento de desintoxicación y un cierto período de abstinencia de bebidas alcohólicas. Parece, por tanto, que la atrofia cerebral de la TC es una medida poco sensible del grado de deterioro del paciente alcohólico, siendo más fiable la exploración psicométrica del rendimiento cognitivo del paciente (Guardia, 1985).
Las indicaciones clínicas para solicitar una TC en el paciente drogodependiente son los déficits cognitivos, alteraciones del E. E. G., focalidad neurológica, abuso de alcohol, antecedentes de traumatismo cráneo-encefálico, antecedentes de convulsiones y trastornos del movimiento.

\subsection{RESONANCIA MAGNETICA CEREBRAL (RM)}

Obtiene imágenes basadas en la resonancia magnética de los protones de los núcleos de hidrógeno. Efectúa mediciones de la densidad de los protones, consigue una mayor resolución que la TC y permite discriminar mejor entre la sustancia blanca y gris, lo cual es de gran utilidad para evaluar lesiones como las de la esclerosis múltiple y las diversas encefalopatías alcohólicas.

Durante la exploración, el paciente se encuentra situado en un campo magnético. Los protones de sus átomos de hidrógeno, en presencia de un campo magnético, se alinean en paralelo, que es el estado de menor energía. Mediante pulsos de radiofrecuencia, se obtienen los dos componentes fundamentales de la RM, T1 y T2, que son los tiempos que tardan en recuperarse los núcleos de hidrógeno, después de la magnetización longitudinal o transversal, respectivamente. La potenciación de dichas imágenes permite visualizar mejor la diferenciación entre materia blanca y gris (T1 potenciado) y la cantidad de agua presente en los tejidos (T2 potenciado), permitiendo distinguir mejor las áreas donde la anatomía es patológica. EI agua y los líquidos tienen T1 y T2 más largos, favoreciendo la visualización de los tejidos edematosos y patológicos. La grasa tiene T1 y T2 más cortos que los líquidos. EI T1 para la sustancia gris es más prolongado que para la sustancia blanca. Las imágenes cargadas con T2 resaltan el líquido cefalo-rraquídeo (LCR), debido a que presenta una degradación del T2 más lenta (Kaplan, Sadock y Grebb, 1996).

\subsubsection{Resonancia magnética estructural (RME)}

El consumo excesivo de alcohol acelera la pérdida de mielina relacionada con la edad y puede contribuir también a la pérdida neuronal en el hipocampo y la circunvolución dentada, que aparecen con un tamaño reducido, que es proporcional a la reducción del volumen cerebral global (Agartz y cols., 1999).

El déficit cognitivo progresa lentamente y algunos estudios consideran que puede empezar a manifestarse cuando la persona ha ingerido más de $1000 \mathrm{Kg}$ de etanol, a lo largo de su vida. Se detecta mediante la evaluación neuropsicológica, ya que la reducción del volumen del cerebro puede ser parcial o totalmente reversible. La RM y la TC sugieren una ligera relación entre la intensidad del consumo de alcohol y la dilata- 
ción del tercer ventrículo. Sin embargo, no ha demostrado una relación consistente entre la severidad del déficit cognitivo, particularmente de la memoria, y la amplitud de la lesión de las estructuras relacionadas con las funciones mnésticas, como el hipocampo y los cuerpos mamilares, posiblemente debido a que dichos cambios estructurales no reflejan con precisión los cambios en la función celular.

Determinadas encefalopatías alcohólicas cursan con alteraciones características cuando se practica una RME. En el Síndrome de Korsakoff la RM revela un aumento de tamaño de los ventrículos cerebrales y de la cisura inter-hemisférica. La atrofia cerebral generalizada es de predominio sub-cortical (Emsley y cols., 1996). También se ha encontrado una disminución del flujo sanguíneo cerebral y de la tasa metabólica en las áreas fronto-temporales y en el tálamo izquierdo, lo cual sugiere una posible disfunción del circuíto frontotalámico (Matsuda y cols., 1997).

En la Encefalopatía de Wernicke, que cursa con oftalmoplejia, ataxia y confusión mental; la RM revela áreas de hiperdensidad en las imágenes cargadas con T2, a nivel del tallo cerebral, tálamo y cuerpos mamilares. Los traumatismos cráneo-éncefálicos, de elevada prevalencia en alcohólicos, pueden empeorar la atrofia cerebral y disminuir el rendimiento de los test neuropsicológicos.

La Encefalopatía por déficit de ácido fólico cursa con una polineuropatía sensorial, de predominio axonal. La RM revela una leucoencefalopatía difusa. Tanto el déficit de ácido fólico como el de cobalamina, pueden interferir en la síntesis de la mielina central (Guettat y cols., 1997).

La Enfermadad de Marchiafava-Bignami, debida a la desmielinización de la porción media del cuerpo calloso, cursa con un síndrome de desconexión hemisférica parecido al de los pacientes que sufren una lesión quirúrgica de las comisuras cerebrales, con síntomas de autismo, alexia, agrafia bilateral, deterioro en la comprensión del lenguaje y déficit de la capacidad constructiva. En la RM aparecen imágenes de lesiones dispersas del cuerpo calloso y lesiones simétricas y extensas del centro semioval, pero el SPECT no muestra áreas de hipoperfusión. Las lesiones de la RM aparecen como hiperintensas en las imágenens con T1 e hipointensas en las efectuadas con T2, lo cual puede ser interpretado como indicador de necrosis central, desmielinización periférica de las lesiones periventriculares y desmielinización del cuerpo calloso. Las lesiones callosas aparecen como placas hiperintensas, parecidas a las de la esclerosis múltiple, con imágenes bien definidas. El núcleo central de baja intensidad podría representar el tejido necrótico y el anillo hiperintenso puede ser debido a gliosis, desmielinización o ambas lesiones a la vez (Ferracci y cols., 1999). Puede afectar también a pacientes no alcohólicos, al igual que el Síndrome de Wernicke-Korsakoff, debido a déficits nutricionales y vitamínicos (Neimman, 1998). El tratamiento con tiamina produce una lenta pero continuada recuperación de los síntomas clínicos y los estudios de RM seriada han encontrado una importante reversibilidad de las alteraciones del cuerpo calloso.

La mielinolisis central pontina (MCP) afecta la sustancia blanca cerebral de la base de la protuberancia. Es una complicación poco frecuente en pacientes con alcoholismo, neoplasias, infección VIH avanzada, parece estar asociada a malnutrición, alteraciones electrolíticas y rápida corrección de la hiponatremia. Cursa con un estado confusional y disfasia. La RM permite observar alteraciones y cambios anatómicos en la protuberancia (Miller y cols., 1998). Se ha propuesto que la MCP puede ser debida a estados de hiponatremia o a su tratamiento y que puede ser una grave complicación tras el trasplante hepático, de manera que una lenta corrección de la hiponatremia a lo largo de la intervención de trasplante puede resultar decisivo para prevenir esta grave complicación.

\subsubsection{Resonancia Magnética Funcional (RMF)}

Permite evaluar procesos fisiológicos como angiografía, flujo sanguíneo y nivel de oxigenación sanguínea, utilizando la desoxihemoglobina como un agente de contraste endógeno y obteniendo una imagen en función del nivel de oxigenación de la sangre. La activación cerebral se manifiesta por una disminución de la desoxihemoglobina, que aparece como una imagen de intensidad regional aumentada. Permite utilizar una inyección de contraste intravascular, como el gadolinium.

\subsubsection{Resonancia Magnética Espectroscópica (RMS)}

Permite detectar el espectro de algunos neurotransmisores de amplia distribución en el cerebro, como el glutamato y el GABA, así como también las concentraciones de determinadas sustancias psicoactivas, como etanol, y su relación con el grado de intoxicación alcohólica aguda, como índice de tolerancia al alcohol. También se puede detectar el espectro de determinados fármacos como litio, antipsicóticos y antidepresivos. Sin embargo no es posible medir otros neurotransmisores que se encuentran en bajas concentraciones, como dopamina.

En los pacientes alcohólicos se ha encontrado una reducción de la sustancia blanca cortical y también de las concentraciones de GABA en el córtex occipital, en pacientes dependientes del alcohol recientemente desintoxicados y en pacientes con encefalopatía hepática, lo cual sugiere que los sistemas GABAérgicos pueden estar alterados en dichos pacientes (Behar y cols., 1999). 
Mediante la detección de N-acetilaspartato y de colina se ha encontrado una reducción de volumen del vermis cerebeloso, en pacientes alcohólicos, con una posible pérdida neuronal asociada a una alteración de la composición celular membrana/mielina, que resulta en una reducción del tamaño cerebral y de la concentración de los citados metabolitos. Con la retirada del consumo de alcohol el volumen cerebral aumenta, debido a la renormalización de la composición celular (membrana/mielina), coincidiendo con una mejoría del metabolismo cerebral; pero la pérdida neuronal persiste. Las áreas más sensibles al alcohol, que suelen presentar atrofia, son los lóbulos frontales y el vermis cerebeloso. Las células de Purkinje del cerebelo son también muy sensibles a la lesión inducida por alcohol (Seitz y cols., 1999).

\subsubsection{Ventajas y desventajas de la resonancia magnética}

La RM estructural proporciona la mayor resolución y contraste disponibles, para los estudios estructurales "in vivo". La RM funcional tiene una mayor resolución espacial que PET y SPECT, con la ventaja añadida que no requiere la administración de fármacos radiotrazadores, lo cual contribuye a que su precio sea cada vez menor y permite además repetidos estudios de una misma persona, en poco tiempo. El rápido progreso de las técnicas de RM resulta muy prometedor para futuros descubrimientos, en el estudio de la neurobiología de los trastornos psiquiátricos (Seibyl y cols., 1999).

\subsection{SPECT CEREBRAL}

EI SPECT, o Tomografía Computarizada por Emisión de Fotón Simple, es una técnica de neuroimagen funcional que utiliza la emisión de fotones gamma, similares a los utilizados en las gammagrafías convencionales. El trazador se fija en el tejido cerebral y se obtienen múltiples imágenes planares del cerebro, desde todos los ángulos posibles. El ordenador reconstruye las imágenes tomográficas, siguiendo los ejes transversal (axial), coronal y sagital. Los tomógrafos que utilizan 2 o 3 cabezales de gammacámara consiguen imágenes de mayor calidad, con una resolución morfológica de 8-10 mm.

\subsubsection{SPECT de perfusión cerebral}

Se utiliza habitualmente el Tecnecio ${ }^{99}$, asociado a Neurolite o H.M.P.A.O., una moléculas lipofílicas, que se fijan al tejido cerebral en proporción directa al flujo sangíneo cerebral (FSC), lo cual es un indicador del metabolismo neuronal e, indirectamente, del funcionalismo cerebral. Su captación es más intensa en el cerebelo, algo menor en el córtex cerebral y ganglios basales, muy baja en la sustancia blanca y nula en el interior del sistema ventricular.

Las imágenes patológicas suelen aparecer como áreas frías o hipocaptantes, debidas a una disminución del FSC (enferemedad cerebrovascular), a lesión del tejido cerebral (atrofia, infarto, cicatriz, lesión ocupante de espacio) o a una disminución del metabolismo neuronal (demencias, enfermedades degenerativas, desconexión córtico-subcortical, etc.). Las imágenes calientes o hipercaptantes aparecen en encefalitis agudas o en determinadas áreas activadas por un foco epiléptico o estados psicóticos.

EI SPECT de perfusión cerebral se ha utilizado para el diagnóstico diferencial de las demencias, para evaluar el efecto de la medicación psiquiátrica y también de los test de activación cognitiva. En pacientes alcohólicos, se ha encontrado una disminición del FSC en áreas frontales y temporales; asociadas a déficits neuropsicológicos de abstracción, resolución de problemas y tareas visuo-motoras. La intensidad de dicha hipoperfusión podría estar también en relación con la presencia de sintomatología de abstinencia del alcohol (Nicolás y cols., 1993).

\subsubsection{SPECT de neurorreceptores}

Los radiofármacos inicialmente utilizados en SPECT, para receptores específicos, han sido el IBZM $\left[{ }^{123}\right]$, para los receptores D2; el [ $\left.\left.{ }^{123}\right]\right] ß-C I T$, para el transportador de serotonina y dopamina; el Iomazenil [1 $\left.{ }^{123}\right]$, para los receptores GABA-benzodiazepínicos y el Ketanserin [ [123], para los receptores serotonérgicos. Se trata de ligandos competitivos con el ligando endógeno, lo cual permite estudiar dicha competitividad con el neurotransmisor fisiológico, según el grado de unión con el receptor específico. Así por ejemplo, la inyección previa de anfetamina, que produce liberación masiva de dopamina, induce una disminución de la disponibilidad de los receptores D2 que va en paralelo con una menor captación de IBZM [I'123] (Catafau, 1998).

\subsubsection{SPECT con IBZM [1/23]}

La iodobenzamida (IBZM), marcada con yodo 123, un antagonista del receptor dopaminérgico D2, análogo del raclopride, se utiliza como ligando o trazador de los neurorreceptores dopaminérgicos D2. Ha permitido confirmar que no existe relación entre el grado de bloqueo de los receptores D2, inducido por diversos antipsicóticos, y la respuesta terapéutica a dichos fármacos, lo cual ha puesto en cuestión la hipótesis dopaminérgica de la esquizofrenia.

EI SPECT con IBZM [ $\left.{ }^{123} \mid\right]$ se ha utilizado para evaluar la ocupación de receptores D2, en el tratamiento neuroléptico de la psicosis, en el tratamiento con LDOPA de la enfermedad de Parkinson y en el diagnóstico diferencial de síndromes parkinsonianos, coreas y 
ataxias. EI SPECT prporciona imágenes de hipocaptación en la enfermedad de Huntington y en los pacientes tratados con antipsicóticos; normocaptación en la enfermedad de Parkinson no tratada y ligera hipocaptación en el Parkinson tratado con L-DOPA (Brücke y cols., 1991). Además, con el aumento de la edad del sujeto explorado, se ha encontrado una disminución progresiva de la densidad de receptores D2, relacionada con el deterioro cognitivo y motor de la persona (Volkow y cols., 1998).

Tras la inyección endovenosa, el trazador o ligando se distribuye por todo el cerebro (fase de unión no específica) y las imágenes iniciales son similares a las del SPECT de perfusión, posteriormente es cuando el radiofármaco se fija al receptor, de manera específica. Cuando la proporción del ligando unido específicamente es igual a la del que queda libre es el momento óptimo para la adquisición de las imágenes del SPECT, ya que la diferencia de captación específica/no específica será máxima. Luego vendrá la fase de lavado en la que el ligando, tras disociarse del receptor, retorna al torrente circulatorio y será metabolizado y eliminado.

Las imágenes, recogidas en 30 minutos, permiten efectuar una valoración cualitativa y también cuantitativa, mediante un índice de captación que se obtiene al comparar la de regiones con unión específica, con la unión no específica. Por ejemplo ganglios basales comparado a córtex frontal u occipital, que sería el índice ganglios basales/frontal o ganglios basales/occipital; cuando se utiliza un ligando de los receptores dopaminérgicos D2.

\subsubsection{SPECT con lomazenil [/ ${ }^{123}$ ]}

El lomazenil [ $\left.{ }^{123}\right]$, que enlaza con los receptores benzodiazepínicos, se ha utilizado en epilepsias, síndromes de ansiedad y tratamiento ansiolítico (Lomeña y Catafau, 1995).

EI SPECT con lomazenil [I ${ }^{123}$, un ligando específico para el receptor GABA-BZ, permite detectar una disminución del número de dichos receptores, en personas dependientes del alcohol, en el córtex frontal, parietal y temporal, incluyendo regiones que no presentaban atrofia de la sustancia gris. La mayor reducción del número de receptores se apreció en el córtex frontal inferior-medial y superior dorso-lateral y en el córtex parietal derecho (sin que, a través de la resonancia magnética, se apreciara una reducción de la sustancia gris) (Lingford-Hughes y cols., 1998).

\subsubsection{SPECT con [123/]ß-CIT}

El [123]]ß-CIT enlaza con el transportador de dopamina y de serotonina, que se encuentran en los lugares de recaptación de las neuronas dopaminérgicas y serotonérgicas pre-sinápticas.
Los pacientes con enfermedad de Parkinson presentan menores lugares de recaptación de dopamina y su intensidad correlaciona con la severidad del deterioro neurológico, mostrando una mayor pérdida en la porción más posterior del núcleo putamen, que en la cabeza del núcleo caudado.

En los pacientes con un Parkinson unilateral, las imágenes asimétricas muestran una menor captación de [ $\left.{ }^{123} \mid\right] ß-C I T e n$ el hemisferio contralateral al del hemicuerpo en que se localizan los síntomas neurológicos.

\subsection{TOMOGRAFIA POR EMISION DE POSITRO- NES (PET)}

Es probablemente la técnica de imagen cerebral más potente en la actualidad. Su inconveniente es que requiere un ciclotrón "in situ", para producir los isótopos, que se pueden incorporar a diversas moléculas fisiológicas (agua, glucosa, aminoácidos, neurotransmisores) o farmacológicas. Permite la medición del metabolismo cerebral, el flujo sanguíneo cerebral (FSC) o la densidad y distribución de determinados receptores o transportadores de neurotransmisores.

Detecta partículas cargadas positivamente (positrones), que se aniquilan con los electrones y emiten dos fotones gamma simultáneamente, con un ángulo de separación de $180^{\circ}$, entre uno y otro. Dicha doble señal permite una localización más precisa del trazador y contribuye a una mejor resolución espacial que el SPECT (Fowler y cols., 1999).

EI PET, con carbono 11, unido a cocaína, premite medir la captación, distribución regional y cinética de dicha droga en el cerebro y su correlación con el estado de euforia ("high") inducido por dicha sustancia (Volkow y cols., 1997b).

También se pueden medir los efectos de una droga sobre el metabolismo cerebral y determinar las regiones cerebrales que son más sensibles a los efectos de la droga, estableciendo asociaciones entre metabolismo (o FSC) y conducta.

En el trastorno obsesivo-compulsivo (TOC), la mayoría de estudios han encontrado un aumento del metabolismo o del FSC en el córtex orbitario y en dos de ellos se ha apreciado un incremento del metabolismo en el núcleo caudado. Tras el tratamiento con clomipramina o I.S.R.S., se produce una disminución del metabolismo de la glucosa, hacia la renormalización en dichas regiones cerebrales. Finalmente, en los estudios de provocación de síntomas, los pacientes con TOC presentaban aumento del FSC en el núcleo caudado derecho, córtex cingulado anterior izquierdo y fronto-orbitario bilateral, coincidiendo con la aparición de síntomas obsesivo-compulsivos y en comparación con el estado de reposo. 
Estos datos sugieren que las urgencias relacionadas con la conducta compulsiva podrían estar relacionadas con la activación del córtex frontal, estriado, $\mathrm{N}$. Pálido y tálamo; mientras que la ansiedad podría estar relacionada con la activación del hipocampo y circunvolución del cíngulo (Saxena y cols., 1998).

En comparación con el SPECT, el PET tiene una mejor resolución anatómica. En ambas técnicas funcionales, las pruebas de activación psicológica o farmacológica permiten delimitar las áreas donde incide dicha activación o las supuestas estructuras cerebrales implicadas en determinadas funciones o patologías. Incluso la exploración previa y posterior a un determinado tratamiento permiten evaluar el pronóstico (previo) o la eficacia del tratamiento (posterior).

\section{PSICOESTIMULANTES}

\subsection{METABOLISMO CEREBRAL Y PSICOESTI- MULANTES}

EI PET con fluorodesoxi-glucosa (FDG) ha comprobado una disminución global del metabolismo cerebral, tras la administración intravenosa de $30 \mathrm{mg}$ de cocaína, por ello se ha propuesto que uno de los mecanismos de refuerzo de la cocaína puede implicar la reducción del metabolismo cerebral.

En cocainómanos recientemente desintoxicados, el metabolismo cerebral, en el córtex órbito-frontal y en el estriado, es mayor que en los controles sanos y la actividad metabólica es más elevada, durante las 72 horas posteriores a la retirada de cocaína, apreciándose una correlación entre el grado de aumento metabólico y la puntuación en el "craving" subjetivo. Como contrapatrida, los que fueron evaluados entre 1 y 4 meses después de la desintoxicación, mostraron reducciones significativas de la actividad metabólica en el córtex prefrontal, órbito-frontal, temporal y circunvolución del cíngulo (Volkow y cols., 1996c).

\subsection{FUNCIONALISMO DOPAMINÉRGICO}

EI PET permite investigar la relación entre los efectos conductuales y potencialmente terapéuticos de un fármaco y el grado de ocupación del receptor o del transportador. Los estudios con raclopride han comprobado que la dopamina sináptica compite con el radioligando y los aumentos en la concentración de dopamina producen una disminución del enlace del radiotrazador, en relación a estudios basales. Pero en los abusadores de cocaína desintoxicados, los cambios en la dopamina sináptica, inducidos por psicoestimulantes aparecen reducidos, comparados a los sujetos control; lo cual sugiere una disminución funcional de la actividad de dopamina cerebral (Volkow y cols., 1997a).

\subsection{Receptores dopaminérgicos $D 2$ y psicoes- timulantes}

Mediante la utilización de la PET con radiofármacos trazadores, se ha encontrado una disminución del número de receptores $\mathrm{D} 2$, que persiste después de la desintoxicación y que se asocia a una disminución de la actividad metabólica del córtex prefrontal, circunvolución del cíngulo y córtex fronto-orbitario (Volkow y cols., 1993a). Dado que los pacientes que consumen cocaína y refieren "craving" intenso, presentan un estado de activación del metabolismo del estriado y del córtex fronto-orbitario (Volkow y cols., 1991), se ha postulado que durante la intoxicación de cocaína, el incremento de dopamina facilita la activación de dichas regiones cerebrales, lo cual conduce al craving y al subsiguiente consumo, de características impulsivas y compulsivas del drogodependiente (Volkow y cols., 1996c).

Los estudios efectuados tras la administración de apomorfina, anfetamina u otros agonistas dopaminérgicos, han encontrado un efecto de reducción de la tasa metabólica en el estriado. En cambio, la administración de haloperidol, antagonista dopaminérgico D2, produce un incremento del metabolismo en los núcleos caudado, putamen y las áreas anteriores del tálamo; a la vez que una disminución del metabolismo en el córtex frontal y cingulado anterior (Holcomb y cols., 1996).

Tras la administración de anfetamina se producen síntomas de euforia, estados de alerta, inquietud y ansiedad. EI SPECT con IBZM detecta una disminución de la disponibilidad de receptores D2, debido a la liberación de dopamina endógena, que correlaciona con la intensidad de los citados síntomas (Laruelle y cols., 1995); resultados parecidos a los que se obtinene utilizando PET con raclopride.

(Volkow y cols., 1999a), comprueban que los sujetos sanos que refieren un efecto reforzador, tras la administración de metilfenidato, presentan niveles más bajos de receptores D2, mientras que el subgrupo de sujetos que refiere efectos más bien desagradables son los que presentan una elevada captación de raclopride que vendría a reflejar elevados niveles de receptores D2. Es decir, que el nivel de receptores D2 podría predecir la respuesta reforzadora de los psicoestimulantes y un bajo nivel de receptores D2 podría contribuir al abuso de psicoestimulantes ya que favorecería el efecto placentero de dichas sustancias (Volkow y cols., 1999a).

Se ha propuesto que existiría un rango óptimo de estimulación del receptor D2 para la producción de efectos reforzadores. Por debajo, la estimulación sería insuficiente para inducir efectos reforzadores y por 
encima produciría efectos aversivos. Es posible que en los sujetos con un elevado número de receptores D2, una pequeña dosis de metilfenidato pueda ser percibida como agradable, pero una dosis elevada podría resultar incluso desagradable. Si el nivel de receptores D2 modula la sensibilidad de los reforzadores fisiológicos, se podría postular que un bajo nivel de receptores D2 podría predisponer hacia el abuso de drogas, mientras que un elevado nivel de receptores D2 podría proteger contra dicho abuso de drogas, ya que podría inducir respuestas desagradables a la drogas.

De hecho, los ratones tratados genéticamente que carecen de receptores D2 presentan una disminución de los efectos reforzadores del alcohol y la morfina y el bloqueo de dichos receptores, mediante fármacos antidopaminérgicos, produce una disminución de los efectos reforzadores de la cocaína, en animales, mientras que en humanos los resultados no han sido tan concluyentes, tal vez porque las dosis empleadas son menores que en los estudios con animales (Volkow y cols., 1999a).

Volkow y cols. (1999a) concluyen, a partir de sus estudios con cocaína, que:

(1) El aumento de liberación de dopamina no es suficiente, por si mismo, para inducir un aumento del metabolismo frontal.

(2) El "craving" de cocaína podría estar asociado a una activación metabólica del córtex fronto-orbitatrio y del estriado.

(3) El circuíto estriado-frontorbitario está implicado en la prominencia de los estímulos reforzadores y su activación puede ser uno de los mecanismos asociados a la pérdida de control y a la administración compulsiva de drogas.

(4) La activación por la dopamina de la circunvolución del cíngulo, una región cerebral implicada en el "drive" o motivación, podría contribuir al deseo de tomar más cocaína, durante la estimulación dopaminérgica, inducida por cocaína.

(5) La correlación predominante del "craving" con el hemisferio derecho, pero no con el izquierdo, require profundizar en la investigación, para comprobar la posible lateralidad de las respuestas reforzadas o condicionadas a las drogas.

\subsubsection{Transportador de dopamina y cocaína}

El transportador de dopamina tiene un papel decisivo en el potencial adictivo de la cocaína. Algunos estudios post-mortem han detectado importantes incrementos de los lugares de enlace al transportador de dopamina (TDA), en muertes relacionadas con cocaína. Mediante SPECT con ß-CIT [I $\left.{ }^{123}\right]$ se ha confirmado un aumento de los lugares de enlace al TDA del estriado, en pacientes con abuso de cocaína. Dicha disfunción dopaminérgica podría ser el trasfondo neurobiológico de la disforia y anhedonia post-cocaína, que aumentan la vulnerabilidad del paciente para la recaída (Malison y cols., 1998).

La disminución del TDA relacionada con la edad, que aparece en los sujetos control, no está presente en los cocainómanos; pero contrasta con los estudios de SPECT con $\beta$-CIT $\left[{ }^{123}\right]$ en los que los cocainómanos mostraron un aumento de la disponibilidad del TDA, durante la abstinencia aguda, que persistiría durante el primer mes de abstinencia de cocaína, requiriéndose períodos más prolongados, de 3 a 15 meses de abstinencia, para conseguir la renormalización del TDA (Malison y cols., 1995).

Mediante PET con metilfenidato, marcado con $\mathrm{C}^{11}$, se ha comprobado también que la inhibición del transportador de dopamina (TDA) por el metilfenidato no consigue bloquear el efecto "high" de una segunda dosis de metilfenidato, administrada 60 minutos más tarde, a pesar del $80 \%$ de ocupación residual del transportador, debido a la primera dosis. Por tanto, parece que la ocupación delTDA no es suficiente para justificar dicho "high" y que se requiere una ocupación superior al 80\% para que los inhibidores del TDA sean terapéuticamente eficaces (Volkow y cols., 1996).

Al comparar la farmacocinética del metilfenidato con la de la cocaína, ambas marcadas con $\mathrm{C}^{11}$, (mediante PET), se encuentra la misma distribución regional en el estriado, compitiendo ambos por los mismos lugares de enlace, pero con marcadas diferencias en su farmacocinética, ya que el aclaramiento de metilfenidato del estriado (90 minutos) es mucho más lento que el de cocaína (20 minutos). Para ambas sustancias, su rápida captación en el estriado discurre en paralelo con la experiencia del "high", disminuyendo rápidamente para el metilfenidato, a pesar de su persistencia en el cerebro. Parece, por tanto, que la experiencia del "high", tanto de cocaína como de metilfenidato, estarían asociadas a su rápida captación por el cerebro, mientras que el lento aclaramiento cerebral del metilfenidato podría ser un factor limitante de su frecuente auto-administración (Volkow y cols., 1995b).

Finalmente, se ha estudiado también la farmacocinética del cocaetileno (metabolito procedente de la administración simultánea de cocaína y etanol), así como los efectos de la intoxicación alcohólica en el cerebro humano (Fowler y cols., 1999).

\subsection{3. "Craving" y cocaína}

Los estímulos condicionados al consumo de cocaína pueden disparar estados de "craving", en los pacientes dependientes de dicha sustancia, que se acompañan de una activación límbica que se manifiesta por un aumento del FSC en la amígdala y la circun- 
volución cingulada anterior y de una disminución del FSC en los ganglios basales, mediante PET. Por tanto, la activación límbica sería un componente del craving de cocaína, inducido por estímulos condicionados.

Los agentes anti-craving que ejerzan una acción de bloqueo de los receptores dopaminérgicos del sistema límbico, como los antagonistas dopaminérgicos, podrían reducir la respuesta de craving inducida por estímulos condicionados Pero el aplanamiento afectivo y motivacional que inducen algunos de ellos contribuye a un bajo cumplimiento, por parte del paciente (Childress y cols., 1999).

\subsubsection{Estructuras cerebrales implicadas en las drogodependencias}

La amígdala es una estructura que tiene una importancia decisiva para el aprendizaje de relaciones entre los estímulos biológicamente relevantes (comida, compañeros sexuales, dolor, etc.) y las señales relacionadas con ellos. En estudios animales se ha comprobado que juega un papel similar en el procesamiento de señales relacionadas con cocaína. La circunvolución cingulada anterior comparte conexiones recíprocas con la amígdala y juega un papel importante en la respuesta emocional y en la atención selectiva. Ambas estructuras están vinculadas anatómicamente con el núcleo accumbens, una región cerebral importante para las propiedades reforzadoras de la cocaína y para la recompensa natural en animales. Dichas estructuras permiten al organismo no sólo experimentar el placer de la recompensa, sinó también aprender las señales anunciadoras que anticipan la recompensa y que pueden ser de gran importancia para la supervivencia individual o de la especie. Durante los estados de "craving", inducidos por estímulos condicionados, el drogodependiente se siente apasionadamente arrastrado por un estado emocional visceral y experimenta un incentivo para actuar muy focalizado que en aquel momento, que no le permite recordar las consecuencias negativas del consumo de aquella droga (Childress y cols., 1999).

El cerebelo, aunque está implicado en la psicomotricidad, puede intervenir también en las propiedades reforzadoras de los reforzadores naturales y de las sustancias psicotrópicas. Tiene conexiones con regiones límbicas cerebrales y su activación podría estar directamente relacionada con la recompensa cerebral. Tanto los psicoestimulantes como el cannabis pueden producir activación del cerebelo, que ha sido asociada a estados de "craving", inducidos por cocaína.

El córtex fronto-orbitario procesa información sobre estímulos reforzadores y aversivos y estaría implicado en los cambios de conducta, cuando se producen modificaciones de las características reforzadoras de dichos estímulos. También se ha relacionado con la expectación del estímulo condicionado, que puede ser percibida conscientemente como "craving". Las lesiones en la región fronto-orbitaria comportan déficits conductuales parecidos a las lesiones del estriado, resultando en perseveración y resistencia a la extinción de las conductas asociadas a la recompensa. Se ha comprobado que dicha patología es patente en la región fronto-orbitaria y el estriado de los pacientes con trastorno obsesivo-compulsivo. La activación del córtex fronto-orbitario y del estriado por metilfenidato, en pacientes dependientes de cocaína, podría ser uno de los mecanismos por los cuales cocaína elicita "craving" y la subsiguiente administración compulsiva de la sustancia en los drogodependientes (Volkow y cols., 1999b).

\section{ALCOHOLISMO}

El alcohol afecta específicamente a los receptores que poseen un canal iónico, como el NMDA y el GABA-BZD. Se ha postulado que en la dependencia del alcohol se produce una hipofunción de la neurotransmisión GABAérgica (Guardia y Prat, 1998).

La administración aguda de alcohol produce una disminución del metabolismo cerebral de la glucosa y un aumento del flujo sanguíneo cerebral. Los alcohólicos presentan una mayor respuesta metabólica tras la administración aguda de alcohol, pero la respuesta subjetiva de intoxicación está disminuída. Esta oposición entre la respuesta metabólica y conductual, en los alcohólicos podría ser el reflejo de la tolerancia del cerebro a los cambios metabólicos inducidos por el alcohol (Volkow y cols., 1996).

\subsection{DESINTOXICACIÓN}

Los estudios efectuados mediante tomografía por emisión de positrones (P.E.T.) han detectado una disminución del metabolismo de la glucosa, en el cerebro, cuando el paciente alcohólico deja de beber, (es decir, durante la etapa inicial del tratamiento de desintoxicación) que correlaciona con los años de abuso de alcohol.

En al segunda etapa de tratamiento, de los 16 a los 30 días de abstinencia, el paciente presenta una renormalización del metabolismo de la glucosa, en el cerebro, que ya no se va a modificar durante el segundo mes de abstinencia. Parece, por tanto, que la renormalización del metabolismo cerebral se produce durante la segunda quincena de tratamiento; siendo el córtex frontal la región que presenta un mayor incremento del metabolismo, tras la desintoxicación, lo cual podría ir en paralelo con la recuperación neuropsicológica del paciente (Volkow y cols., 1994). 


\subsection{ABSTINENCIA PROLONGADA}

El síndrome de abstinencia prolongada, que cursa con ansiedad, síntomas depresivos, hiperexcitabilidad del S.N.C. e insomnio, suele aparecer durante los 6 primeros meses de abstinencia, aunque puede reaparecer, de forma episódica, hasta 15 años después y se ha considerado que está asociado a un mayor riesgo de recaída, durante los 3-6 primeros meses de recuperación.

La disminución del metabolismo, en los ganglios basales, que se aprecia tras la retirada del alcohol, parece persistir durante el $2^{\circ}$ mes de tratamiento, lo cual podría estar en relación con los síntomas persistentes de abstinencia, trastorno del sueño y/o "craving", que presentan los pacientes en recuperación, que han sido englobados en el concepto del síndrome de "abstinencia prolongada" y que han sido relacionados con un riesgo aumentado de recaída, para determinados pacientes, sobretodo durante los tres primeros meses de recuperación (Volkow y cols., 1994).

\subsection{PERFUSIÓN CEREBRAL CON COCAÍNA Y ALCOHOL}

La tasa de abuso de alcohol entre los abusadores de cocaína es muy elevada. Los pacientes alcohólicos presentan reducciones en la perfusión sanguínea del córtex frontal. Se describieron inicialmente en pacientes con síndrome de Korsakoff y se comprobó que su perfusión cerebral retornaba a la normalidad a los 4 meses de evolución, cuando el síntoma confabulación había remitido.

En un estudio efectuado con abusadores de cocaína y alcohol, mediante SPECT con HMPAO, se ha detectado una reducción del FSC en 11 de 14 regiones cerebrales, sobretodo en el córtex frontal y parietal y un aumento del FSC en el tronco cerebral. Los defectos en la perfusión frontal experimentan una mejoría parcial, durante los 21 días que ha durado la desintoxicaión, pero no los que corresponden a la región parietal (Kosten y cols., 1998).

\section{4. "CRAVING"}

Uno de los mayores obstáculos para la recuperación de las personas dependientes del alcohol es su elevada tasa de recaídas. En los últimos años, ha surgido un gran interés por uno de los síntomas motivacionales relacionados con los procesos de recaída, es el llamado "craving" y se define como un intenso y prolongado deseo de droga, ansioso o anhelante.
El "craving", que podría estar en relación con el deseo de repetir la experiencia de los efectos agradables previamente experimentados con las sustancias psicoactivas, podría contribuir tanto al consumo continuado, como a la conducta de recaída, después de largos períodos de abstinencia.

Los procesos de condicionamiento a los efectos reforzadores de las sustancias psicoactivas y de su abstinencia es uno de los factores subyacentes al "craving", que contribuyen a desencadenar conductas de recaída. En otras palabras, la presencia de estímulos condicionados, relacionados con el consumo de alcohol, puede desencadenar intensos sentimientos, sensaciones, pensamientos y deseo imperioso de ingerir bebidas alcohólicas.

\subsubsection{Hipótesis dopaminérgica del "craving"}

Diferentes estudios, han determinado que las alteraciones sobre el sistema de neurotransmisión dopaminérgico, que se producen como consecuencia del consumo crónico de sustancias psicoactivas, podría ser uno de los sustratos neurobiológicos del "craving". Dichas alteraciones en la neurotransmisión dopaminérgica facilitarían que, tanto el propio consumo de alcohol, como cualquier estímulo condicionado que produzca una activación dopaminérgica, puedan inducir estados de "craving", conductas de búsqueda y consumo de alcohol, y el consiguiente proceso de recaída (Guardia y Prat, 1997).

La tomografía por emisión de fotones (SPECT) con $\mathrm{HMPAO}\left(\mathrm{TC}^{99 \mathrm{~m}}\right)$, en 9 pacientes con dependencia del alcohol, a los que se les había inducido un estado de "craving", ha encontrado un aumento del flujo sanguíneo cerebral (FSC) en la cabeza del núcleo caudado derecho, existiendo una correlación entre el grado de aumento del FSC y la intensidad del craving, lo cual sugiere un papel funcional del estriado límbico en la mediación del "craving" y de la pérdida de control sobre el consumo de alcohol. Este resultado podría apoyar la hipótesis de que el craving y la dificultad para controlar el consumo son inducidos o exacerbados por los efectos dopaminérgicos de la ingestión de alcohol. Tanto los estímulos condicionados, como el propio consumo de alcohol producirían un aumento del tono inhibitorio dopaminérgico que ejercen las neuronas que parten del área tegmental ventral (ATV) sobre el núcleo caudado/accumbens, asociado a un aumento de la actividad neuronal fronto-talámica y fronto-estriado/accumbens. Un efecto que podría ser neutralizado por un antagonista D2, como haloperidol.

Por otro lado, al aumento del FSC en la cabeza del núcleo caudado derecho podría reflejar el intento del sujeto para inhibir el impulso a beber, que habría sido disparado por el "craving", que podría ir acompañado de la sensación subjetiva de capacidad para resistirse a la bebida (Modell y Mountz, 1995). 


\subsubsection{Neuroimagen del TOC. Similitudes con el "craving" y la conducta compulsiva}

En el trastorno obsesivo-compulsivo se ha encontrado también un aumento del FSC en la cabeza del núcleo caudado derecho, así como también en el córtex cingulado anterior izquierdo y orbitofrontal bilateral, sobretodo tras la inducción de síntomas obsesivocompulsivos (una alteración que tendería a renormalizarse con la terapia cognitivo-conductual de exposición y prevención de respuesta y que apoyaría la hipótesis de una alteración del sistema prefrontal cortico-estriado-talámico, en la mediación de los síntomas del trastorno obsesivo-compulsivo). Parece, por tanto, que el núcleo caudado estaría implicado en la mediación de síntomas obsesivo-compulsivos o de la inhibición conductual. La lateralización hacia el hemisferio derecho podría estar relacionada con la naturaleza no verbal y cargada emocionalmente, tanto del craving como de los síntomas compulsivos.

Jenike y cols. (1996) proponen que los diversos síntomas del trastorno obsesivo-compulsivo podrían estar en relación con tres sustratos neurobiológicos diferenciables, los síntomas cognitivos estarían en relación con un circuíto que partiendo del córtex prefrontal lateral y órbito-frontal anterolateral, enlazaría con caudado, pálido, sustancia negra, tálamo y, finalmente, retornaría al córtex frontal antero-lateral. Este circuíto sería el responsable del aumento del FSC del núcleo caudado derecho, en el trastorno obsesivocompulsivo. Mientras que los síntomas emocionales y motivacionales estarían en relación con con un circuíto que partiendo del córtex paralímbico, cingulado anterior y órbito-frontal postero-medial, enlazaría con el núcleo accumbens. Finalmente, el circuíto relacionado con los síntomas sensorio-motores, partiría del córtex sensorio-motor y enlazaría con el núcleo putamen, estando alterado en trastornos como el síndrome de la Tourette, tricotilomanía o tics.

De hecho, el fenómeno del craving tiene también diversas dimensiones sintomáticas: cognitiva, emocional, motivacional, sensorio-motora, conductual, etc. Se podría diversificar también en un craving cognitivo, que sería el deseo de beber más consciente, un craving emocional y motivacional que podrían ser menos conscientes o incluso inconscientes y el craving sensorio-motor consistiría en unas pautas de conducta estereotipada, relacionada con los estímulos condicionados; y cada una de dichas dimensiones del craving podría estar relacionada con los citados circuítos.

Los estudios de provocación de síntomas, mediante la exposición a estímulos obsesivo-fóbicos, en pacientes obsesivo-compulsivos, han detectado activación de los córtex isocortical (frontal lateral), paralímbico (circunvolución orbital medial, córtex cingulado anterior y córtex insular), límbico (amígdala) y estriatal (caudado y lenticular); asociado a los síntomas obsesivo-compulsivos. Estarían implicados, por tanto, sistemas relacionados tanto con cognición como con emoción (Breiter y cols., 1996).

Mediante SPECT de perfusión se ha encontrado una mayor "ratio" entre el córtex fronto-medial y el resto del córtex, en pacientes con TOC y sin medicación, comparados a sujetos control. Dicha alteración se renormalizó tras 3-4 meses de tratamiento con fluoxetina, en paralelo a la remisión de los síntomas obsesivo-compulsivos. También se han encontrado aumentos de la captación bilateral en áreas corticales y disminución de la captación bilateral de HMPAO en la cabeza del caudado, en elTOC no tratado.

En los estudios de provocación de síntomas obsesivo-compulsivos, por exposición a estímulos de contaminación, se ha detectado una disminución del flujo snguíneo cerebral en todas las regiones corticales, (excepto córtex temporal). Tal vez debido a un secuestro de la sangre de las áreas corticales de la superficie a otras áreas como el núcleo caudado o la circunvolución orbitaria, que no pueden ser visualizadas cuando se utiliza el xenon 133, como trazador. Por tanto parece que los pacientes con TOC presentan una hiperperfusión cortical, que se exacerba con la provocación de síntomas, ya sea con estímulos condicionados o bien farmacológicamente, mediante m-clorofenilpiperazina, un agonista serotonérgico que agrava los síntomas obsesivo-compulsivos (Saxena y cols., 1998)..

La neuroanatomía del trastorno obsesivo-compulsivo ha descrito dos cicuítos fronto-subcorticales. Una vía directa de retoralimentación positiva o activadora, que partiendo del córtex prefrontal se dirige hacia el estriado, segmento interno del globo pálido, sustancia negra y retorna hacia el tálamo y posteriormente hacia el córtex prefontal. Y una vía indirecta, de retroalimentación negativa o inhibitoria, que partiendo también del córtex prefrontal se dirige también hacia el estriado, segmento externo del globo pálido, núclo sub-talámico, globo pálido interno y sustancia negra reticular, para retornar finalmente hacia tálamo y córtex frontal.

Los impulsos de la vía directa, (que contiene neurotransmisores como glutamato, GABA, sustancia P y dinorfina), producen la desinhibición del tálamo y la activación de sistemas de retroalimentoación positivos, de manera auto-reververante. Mientras que los impulsos que transcurren por la vía indirecta (que dispone de neurotransmisores como GABA y encefalinas) producen una retroalimentación negativa, con un efecto de inhibición talámica. De esta manera, la activación de uno u otro circuíto producirían respectivamente facilitación o supresión de programas motores complejos.

La patofisiología del TOC consistiría en un desequilibrio entre el tono excesivo de la vía directa (activadora) relativamente superior al de la vía indirecta (inhibitoria), del circuíto fronto-orbitario-subcortical; de tal 
manera que los estímulos socio-territoriales (violencia, higiene, orden, sexo, etc.) "capturan" el sistema, las preocupaciones y la respectiva conducta compulsiva consiguen bloquear el sistema, produciéndose una dificultad para inhibir la conducta compulsiva y para cambiar a otras conductas. (Saxena y cols., 1998).

En las drogodependencias, los estímulos condicionados no serían los socio-territoriales sino los que están condicionados a la recompensa cerebral y asociados a la conducta de auto-administración de drogas. Es decir, aquellos estímulos que anunciarían la disponibilidad de droga, los cuales activarían la vía directa, produciendo un desequilibrio de activación del circuíto fronto-orbitario-subcortical, que "capturaría" el sistema y dejaría vía libre a la conducta de auto-administración de la sustancia que no podría ser bloqueada por la vía indirecta, la cual tiene una función de inhibición conductual; ya que en tales circunstancias su tono es inferior al de la vía directa.

\subsection{SISTEMA OPIOIDEY ALCOHOLISMO}

Etanol y opiáceos presentan efectos farmacológicos y adictivos parecidos, por lo que pueden tener un sustrato neurobiológico común. El sistema opioide puede actuar como mediador de los efectos reforzadores del alcohol y como modulador del consumo de alcohol, estando relacionado con el efecto de pérdida de control.

El etanol, en administración aguda, produce una activación de los receptores opioides, que probablemente sea debida a la liberación de opioides endógenos, particularmente $\beta$-endorfina. La administración crónica de etanol puede producir modificaciones en la neurotransmisión opioidérgica, alterando la sensibilidad de los receptores opioides.

Determinadas personas podrían obtener mayores efectos reforzadores del alcohol, debido a bajos niveles basales de $\beta$-endorfina, que contrastan con una importante liberación de dicho opioide tras el consumo de alcohol.

La manipulación farmacológica del sistema opioide endógeno, altera el consumo de alcohol en animales de laboratorio, de manera que los agonistas opioides, a dosis bajas, aumentan el consumo de etanol y a dosis elevadas lo disminuyen. Mientras que los antagonistas disminuyen el consumo de alcohol, a través de una disminución de su valor reforzador positivo.

El etanol, a través de un efecto indirecto de activación de determinados receptores opioides, produce liberación de dopamina en el núcleo accumbens, lo cual está implicado en el "craving" y la conducta de búsqueda de alcohol. Un efecto que puede ser revertido por naltrexona, al igual que el fenómeno de la interrupción forzada, o el del estrés incontrolable, que producen un incremento del consumo de alcohol (Guardia y cols., 1998).

\subsubsection{Antagonistas opioides en el alcoholismo}

En un estudio efectuado en el Hospital de Sant Pau de Barcelona, se ha utilizado el SPECT de perfusión cerebral con HMPAO [TC ${ }^{99 m}$, para evaluar los efectos de la naltrexona. Se han practicado un SPECT basal y otro tras haber tomado $150 \mathrm{mg}$ de naltrexona a 16 pacientes dependientes del alcohol, una vez finalizado el tratamiento de desintoxicación, en régimen de hospitalización completa.

En el SPECT basal, los pacientes alcohólicos presentaban un menor flujo sanguíneo cerebral (FSC) en el córtex fronto-orbitario y prefrontal, que los sujetos control, lo cual podría estar en relación con el menor rendimiento cognitivo que presentan los pacientes alcohólicos durante la primera quincena, tras haber dejado de beber.

Tras la administración de naltrexona, los pacientes alcohólicos presentaban una disminución del FSC, en los ganglios basales (bilateral) y en la región temporal mesial izquierda; en comparación a su SPECT basal. Por tanto, tras la administración de naltrexona se produciría una reducción de la actividad metabólica, en regiones ricas en receptores opioides, que además están implicadas en la memoria emocional y en los aspectos obsesivo-compulsivos del "craving" (Catafau y cols., 1999).

Es decir, que el efecto anti-craving de la naltrexona, en pacientes alcohólicos, podría estar asociado a una reducción del FSC en ganglios basales y estructuras límbicas (como la amígdala), situadas en la región temporal mesial, de manera parecida a los que se producen en el paciente obsesivo-compulsivo que mejora tras el tratamiento con ISRS o terapia cognitivo-conductual.

\subsection{RECEPTORES DOPAMINERGICOS Y ALCO- HOLISMO}

Además del SPECT o el PET de perfusión cerebral, cuando las moléculas con isótopos radiactivos se acoplan específicamente a un determinado tipo de receptor cerebral, podemos visualizar el funcionalismo de algunos sistemas de neurotransmisión. Tal es el caso del la yodobenzamida, marcada con yodo 123 (IBZM$\left.\mathrm{I}^{123}\right)$, que permite el estudio de la distribución, densidad y grado de ocupación de los receptores dopaminérgicos D2 en humanos (Kung y cols., 1990; Verhoeff y cols., 1993).

La administracion aguda de alcohol no modifica la captación de raclopride (antagonista dopaminérgico D2) por los receptores dopaminérgicos D2 en el estriado humano, pero si produce una diferente latera- 
lización de dicha captación en voluntarios sanos (Salonen y cols., 1997).

En un estudio de 9 pacientes con dependencia del alcohol y 8 sujetos control, mediante tomografía por emisión de positrones (PET) con raclopride $\left(\mathrm{C}^{11}\right)$, se ha detectado una tendencia (no significativa) hacia una menor captación de raclopride, en comparación a los sujetos control, lo cual sugiere una reducida avidez de los receptores D2 para la dopamina, en el estriado, que podría estar en relación con la neurobiología de la dependencia del alcohol, aunque el poder estadístico de una muestra tan pequeña es insuficiente (Hietala y cols., 1994).

En otro estudio con 10 pacientes alcohólicos, entre 5 y 180 días después del último consumo de alcohol, utilizando también raclopride $\left(\mathrm{C}^{11}\right)$, y un inhibidor del transportador de dopamina (metilfenidato[ $\left.\mathrm{C}^{11}\right]$ ), se ha comprobado una menor captación de raclopride, sin que existiera correlación con el número de días desde el último consumo de alcohol. Sin embargo, los pacientes alcohólicos no presentaron diferencias en cuanto a la disponibilidad del transportador de dopamina (Volkow y cols., 1996a).

En la primera etapa del estudio efectuado en el Hospital de Sant Pau de Barcelona, mediante SPECT con IBZM [l'123], no hemos encontrado, diferencias en la captación de IBZM entre pacientes alcohólicos y los sujetos control, pero sí entre pacientes que recaen y los que no han recaído, a los 3 meses de recuperación, post-desintoxicación.

Al evaluar los primeros 21 pacientes dependientes del alcohol, comparados con 9 sujetos control, se ha comprobado que los pacientes que tuvieron una recaída, a lo largo de los 3 primeros meses de recuperación, presentaban una mayor captación de IBZM [I'23], en ganglios basales, que los pacientes que no recayeron durante dicho período.

Estos resultados sugieren que bajos niveles de dopamina en las sinapsis de los ganglios basales, o una mayor densidad de receptores dopaminérgicos D2, podrían estar relacionados con la recaída precoz en los pacientes alcohólicos. Por tanto, el SPECT con IBZM [| $\left.{ }^{123}\right]$ podría llegar a convertirse en un marcador biológico de vulnerabilidad hacia la recaída, para los pacientes alcohólicos que se encuentran en recuperación (Guardia y cols., 2000).

\subsection{RECEPTORES GABA-BZDY ALCOHOLISMO}

La preferencia del alcohol, en las ratas HAD podría estar relacionada con un aumento de los terminales GABA y de la inhibición GABAérgica, localizada en el núcleo accumbens, ya que dichas ratas presentan un aumento del número de terminales GABAérgicos en el núcleo accumbens, una estructura relacionada con los efectos reforzadores del etanol.
L'administración crónica de etanol induce una disminución de la neurotransmisión GABAérgica y un incremento de la glutamatérgica, que contribuyen a la hiperexcitabilidad neuronal y a las crisis convulsivas, que pueden aparecer durante el síndrome de abstinencia del alcohol (Guardia y Prat, 1997).

Los hijos e hijas de enfermos alcohólicos, que tienen un riesgo elevado de desarrollar también alcoholismo, pueden presentar una menor sensibilidad de los receptores GABA $A^{-B Z D, ~ y a ~ q u e ~ p r e s e n t a n ~ u n a ~}$ menor sensibilidad al alcohol (Schuckit i cols., 1996) y un aumento de la respuesta euforizante a las benzodiazepinas (BZD), cosa que podría sugerir una vulnerabilidad compartida tanto para la dependencia del alcohol, como de las BZD, en hijos de pacientes alcohólicos. Además presentan también una respuesta menos intensa, de disminución del metabolismo cerebral de la glucosa, en regiones fronto-subcorticales y cerebelosas, después de la administración de BZD (Volkow y cols., 1995a).

Otros autores han confirmado una disminución de la neurotransmisión inhibitoria, en pacientes alcohólicos, debido a una alteración del circuítos que enlazan el cerebelo con el tálamo, ganglios basales y córtex fronto-orbitario, que podría estar relacionada con la dificultad en el inicio y la finalización de determinadas conductas y, por tanto, con las conductas compulsivas y la pérdida de control (Volkow y cols., 1993b).

Recientemente se ha detectado un nuevo polimorfismo en el alelo del aminoácido Pro385Ser, del gen de la subunidad $\alpha 6$ del recceptor GABA-BZD. Los hijos de alcohólicos que tienen el alelo Ser385, presentan una menor sensibilidad al alcohol (Schuckit i cols., 1999) y también al diazepam (Iwata y cols., 1999).

Parece, por tanto, que determinadas diferencias en la subunidad $\alpha 6$ del receptor GABA-BZD, que podrían ser transmitidas genéticamente, estarían implicadas en una menor sensibilidad al alcohol y al diazepam, lo cual podría ser un factor de vulnerabilidad para el abuso de dichas sustancias.

Por otro lado, mediante RM espectroscópica se han detectado bajos niveles de GABA en el córtex cerebral de pacientes alcohólicos desintoxicados y también en pacientes con encefalopatía hepática, lo cual sugiere una posible alteración de los sistemas GABAérgicos en pacientes alcohólicos (Behar y cols., 1999).

El hecho que el número de receptores GABA-BZD esté disminuído en diversas regiones corticales i en el cerebelo, de los pacientes alcohólicos, podría ser un indicador tanto del efecto tóxico del alcoholismo sobre dichos receptores, como de una mayor vulnerabilidad para el desarrollo del alcoholismo (Abi-Dargham y cols., 1998). 
Mediante SPECT con Iomazenil [ [ $\left.{ }^{123}\right]$, se ha encontrado una reducción del número de receptores GABA$B Z D$, en personas dependientes del alcohol, en el córtex frontal, parietal y temporal, que incluyen regiones que no presentan atrofia de la sustancia gris, sobretodo en el córtex frontal inferior-medial y superior dorsolateral y en el córtex parietal derecho (Lingford-Hughes y cols., 1998).

Finalmente, los pacientes alcohólicos presentan una disminución del metabolismo cerebral de la glucosa, tanto tras la administración de etanol, como de BZD, y también una respuesta metabólica aplanada al lorazepam, en el córtex órbito-frontal, que persiste tras la desintoxicación (Volkow y cols., 1997c). Pero también las personas no alcohólicas, que tienen antecedentes familiares de alcoholismo (AFA), presentan una respuesta metabólica diferente que la de las personas que no tienen dichos antecedentes familiares, lo cual sugiere posibles diferencias genéticas, previas al inicio del alcoholismo, relacionadas con el receptor GABA-BZD, que podrían aumentar la vulnerabilidad de las personas con AFA, tanto para la dependencia del alcohol, como de las BZD. Sin embargo, estos autores no han encontrado diferencias en el número de receptores GABA-BZD, explorados mediante flumazenil [C11] (Fowler y cols., 1999).

\subsection{TRANSPORTADOR DE SEROTONINA Y DOPAMINA}

Utilizando el SPECT con el radiofármaco $\beta$-CIT(|| $\left.{ }^{123}\right)$, que permite investigar la distribución y densidad de los lugares de recaptación de dopamina, se ha comprobado que la densidad del transportador de dopamina estaba disminuída en los alcohólicos no violentos y aumentada en los alcohólicos violentos en comparación a los controles sanos. Parece, por tanto, que ambos tipos de alcohólicos presentan alteraciones en el sistema dopaminérgico estriatal, aunque en direcciones opuestas (Tiihonen y cols., 1995).

Pero no coincide con el estudio posterior de Volkow y cols. (1996a) que encuentran una disminución de receptores D2, en ganglios basales, pero no del transportador de dopamina.

Por otro lado la captación de $\beta$ CIT [1 $\left.{ }^{123}\right]$ aparece aumentada en el estriado, tanto en el síndrome de la Tourette (Malison y cols., 1995), como durante la abstinencia aguda de cocaína (Malison y cols., 1988), apoyando la hipótesis de una disregulación de la función dopaminérgica presináptica; mientras que en la enfermedad de Parkinson aparece disminuída, debido a una reducción del número de neuronas dopaminérgicas.

Diversos estudios sugieren que la disfunción serotonérgica puede aumentar la vulnerabilidad biológica hacia la dependencia del alcohol. Entre los jóvenes varones, los rasgos de personalidad antisocial y una menor sensibilidad para la intoxicación alcohólica pueden predecir el subsiguiente abuso y dependencia del alcohol (Schuckit y cols., 1996).

Un bajo "turnover" de serotonina, en el SNC (medido con niveles de 5HIAA en LCR), se ha asociado a la patogénesis del abuso de alcohol y a la conducta impulsivo-agresiva y los bajos niveles de 5HIAA, en LCR, en alcohólicos de inicio precoz, han sido asociados a un curso más severo del alcoholismo, problemas de aislamiento social y un deterioro del funcionamiento social (Heinz y cols., 1998a).

Se ha encontrado una correlación negativa entre la captación de $\beta$ CIT, por los transportadores de serotonina, en el tronco cerebral (donde se encuentran los núcleos del rafe, origen de las neuronas serotonérgicas), y la concentración de 5HIAA en LCR. Los primates que presentaban mayor captación de $\beta$ CIT (debido a una mayor disponibilidad del transportador de serotonina) y una baja concentración de 5HIAA en LCR, mostraban también mayor agresividad y menor sensibilidad a la intoxicación inducida por el alcohol. Por tanto, los primates que sufrieron un estrés ambiental, en su desarrollo precoz, presentaban las variables indicadoras de un bajo "turnover" de serotonina y patrones de conducta similares a los que predisponen al alcoholismo, de inicio precoz, en humanos y su neuroimagen era de mayor captación de $\beta$ CIT (Heinz y cols., 1998a).

En humanos, una bajo nivel de 5HIAA en LCR ha sido asociado a conducta agresiva y alcoholismo de inicio precoz y se ha sugerido que el factor patogénico en la dependencia del alcohol sería la capacidad funcional disminuída de los transportadores de serotonina. En pacientes alcohólicos recientemente desintoxicados, se ha encontrado una reducción de la captación de $\beta$ CIT [ $\left.{ }^{123}\right]$ en la región dorsal del tronco cerebral, donde se encuentran situados los núcleos del rafe, ricos en cuerpos celulares y lugares de recaptación de serotonina (Heinz y cols., 1998b).

Dado que la reducción en la captación de $\beta$ CIT [1 $\left.{ }^{123}\right]$ correlaciona negativamente con el consumo total de alcohol, a lo largo de la vida, ansiedad y depresión; parece que la intoxicación crónica de alcohol reduce la densidad del transportador de serotonina, lo cual cursa con ansiedad y depresión, aumentando el riesgo de recaída en los alcohólicos y generando el círculo vicioso de la dependencia del alcohol. Todo ello apoyaría la hipótesis de la disfunción serotonérgica, tanto en el alcoholismo, como en los síntomas depresivos que suelen aparecer durante la recuperación del alcoholismo.

La reducción de la captación de $\beta$ CIT [ [123] por el transportador de serotonina puede ser debida tanto a un aumento de las concentraciones de serotonina en la sinapsis como a una disminución de la densidad o afinidad del transportador. Dado que durante la absti- 
nencia del alcohol se produce una disminución del "turnover" de serotonina, parece improbable que la reducción de $\beta$ CIT [ [123] en los núcleos del rafe sea debido a un aumento de la concentración de serotonina en la sinapsis, sino mas bien atribuíble a una reducción en la densidad del transportador, a consecuencia de los efectos tóxicos acumulativos del consumo de etanol (Heinz y cols., 1998b).

\section{OTRAS DROGODEPENDENCIAS}

Los fumadores de cigarrillos presentan una reducción de la MAO-B cerebral de un $40 \%$ y de la MAO-A cerebral de un $28 \%$, en comparación a los no fumadores y a los exfumadores. Dicha inhibición de la MAO ( $A$ y $B$ ) estaría asociada con un aumento de la actividad de la dopamina, lo cual podría explicar la comorbilidad del tabaquismo con la depresión y con la dependencia de otras sustancias. La eficacia de los inhibidores de la MAO, en el tratamiento de la depresión, es un hecho claramente contrastado. Sin embargo, no aparecen diferencias en el metabolismo cerebral de la glucosa, entre fumadores y no fumadores.

La resonancia magnética funcional permite identificar las regiones neuroanatómicas que se activan por la nicotina. Tras la administración intravenosa de nicotina se produce una activación del córtex frontal (dorsolateral, orbitario y frontal medial) y también de la circunvolución del cíngulo. Se ha propuesto que dichas regiones podrían estar implicadas en los efectos conductuales y de alteración del ánimo que produce la nicotina (Stein y cols., 1998).

Durante la intoxicación por marihuana se ha encontrado una activación predominante de regiones cerebrales derechas, una imagen parecida a la que se produce durante el "craving" de alcohol, que se ha asociado con aumentos del FSC en el caudado del hemisferio derecho (Modell y Mountz, 1995). Además, se produce una activación cerebelosa (mediante PET con FDG) que va en paralelo con las alteraciones en la coordinación motora y la propiocepción (Fowler y cols., 1999) y que podría estar en relación con el hecho de que el cerebelo tiene una elevada concentración de receptores para elTHC.

\section{APORTACIONES DE LA NEUROIMAGEN A LAS DROGODEPENDENCIAS}

La neuroimagen puede evaluar los efectos de las sustancias psicoactivas sobre el cerebro humano; establecer relaciones entre la respuesta conductual y los efectos sobre determinadas regiones cerebrales, tanto sobre su funcionalismo (FSC o metabolismo de glucosa), como sobre determinados neurotransmisores; evaluar los efectos de la abstinencia de una sustancia o del tratamiento con un fármaco; estudiar los cambios neuroquímicos y funcionales, en comparación con sujetos control y aplicar los nuevos conocimientos para el desarrollo y evaluación de nuevas intervenciones terapéuticas (Fowler y cols., 1999).

En el futuro la investigación sobre neuroimagen podría orientarse hacia la:

Asociación con mediciones conductuales (ej.: cuestionarios de craving, inventarios de estado de ánimo, reactividad a estímulos, paradigma de autoadministración) o técnicas de administración de una sustancia, para perfilar los circuítos neuroánatómicos y bioquímicos que subyacen a sus propiedades reforzadoras, durante la intoxicación o la abstinencia. La utilización de radioligandos (mediante PET y SPECT) que caractericen los procesos neuroquímicos asocidos al refuerzo o craving de alcohol, que incluyen la liberación de neurotransmisores, concentración de receptores, síntesis de neurotransmisores y transportadores de neurotransmisores. El estudio de los circuítos que subyacen a los déficits cognitivos asociados a la ingesta aguda y crónica de alcohol, particularmente los estudios que pueden aclarar de qué manera los déficits funcionales de determinados circuítos "neuroanatómicos", y sus déficits cognitivos relacionados, pueden contribuir al consumo excesivo de alcohol. Y, finalmente, el desarrollo de marcadores neurobiológicos de vulnerabilidadd hacia la dependencia de sustancias psicoactivas en niños y/o adolescentes, sobretodo mediante técnicas como la RME o RMF, que no requieran trazadores radiactivos; las cuales podrían ser de gran utilidad para la detección de poblaciones de riesgo de drogodependencias. Un método imprescindible para poder efectuar una verdadera prevención primaria de las drogodependencias.

\section{BIBLIOGRAFIA}

1. Abi-Dargham A; Krystal Jh; Anjilvel S; Scanley Be; Zoghbi S; Baldwin Rm; Rajeevan N; Ellis S; Petrakis II; Sebyl Jp; Charney Ds; Laruelle M; Innis Rb: (1998) Alterations in benzodiazepine receptors in tipe II alcoholic subjects measured with SPECT and [123I] Iomazenil.Am. J. Psychiatry 155: 1550-1555.

2. Agartz I; Momenam R; Rawlings RR; Kerich MJ; Hommer DW.: (1999) Hippocampal volume in patients with alcohol dependence. Arch. Gen. Psychiatry 56:356336.

3. Behar KL; Rothman DL; Petersen KF; Hooten M; Delaney R; Petroff O; Shulman GI; Navarro V; Petrakis IL; Charney DS; Krystal JH: (1999) Preliminary evidence of low cortical GABA levels in localized $1 \mathrm{H}-\mathrm{MR}$ spectra 
of alcohol-dependent and hepatic encephalopathy patients. Am. J. Psychiatry 156:925-954.

4. Breiter HC; Rauch SL; Kwong KK; Baker JR; Weisskoff RM; Kennedy DN; Kendrick AD; Davis AD; Jiang A; Cohen MS; Stern CE; Belliveau JW; Baer L; O'Sullivan RL; Savage CR; Jenicke MA; Rosen BR: (1996) Functional margentic resonance imaging of symptom provocation in obsessive-compulsive disorder.Arch. Gen. Psychiatry. 53:595-606.

5. Brücke T; Podreta I; Angelberer P; Wenger S; Topitz A; Küfferle B; Müller Ch; Deecke L: (1991) Dopamine D2 receptor imaging with SPECT studies in different neuropsychiatric disorders.J. Cereb. Blood Flow Metab. 11:220-228.

6. Catafau AM: (1998) Spect cerebral de neurorreceptores: el estudio in vivo de la acción central de los antipsicóticos. Revisiones en Psicofarmacología 2:7-13.

7. Catafau AM; Etcheberrigaray A; Perez de los Cobos J; Estorch M; Guardia J; Flotats A; Bernà L; Marí C; Casas M; Carrió I: (1999) Regional cerebral blood flow changes in chronic alcoholic patients induced by naltrexonae challenge during detoxification. J. Nucl. Med. 40:19-24.

8. Childress AR; Mozley PD; McElgin W; Fitzgerald J; Reivich M; O’Brien CP: (1999) Limbic activation during cue-induced cocaine craving. Am. J. Psychiatry 256:11-18.

9. Emsley R; Smith R; Roberts M; Kapnias M; Pieters H; Maritz S.: (1996) Magnetic resonance imaging in alcoholic Korsakoff's syndrome: evidence for an association with alcoholic dementia. Alcohol Alcohol. 31:479-486.

10. Ferracci F; Conte F; Gentile M; Candeago R, Foscolo L; Bendini M; Fassetta G.: (1999) Computed tomographic scan 99mTc HMPAO-SPECT, and FLAIR MRI findings in a patient with subcortical aphasia, alexia, bilateral agraphia, and left-handed deficit of constructional ability. Arch. Neurol. 56:107-110.

11. Fowler JS; Volkow ND; Malison R; Gatley SJ: Neuroimaging studies of substance abuse disorders. In: Charney DS; Nestler EJ; Bunney BS (Eds.) Neurobiology of mental illness. New York. Oxford University Press, 1999 (p. 616-626)

12. Guardia Serecigni J; Freixa F; Bach L; Ruscalleda J; M. dos Santos F; Guardia E; Carvajal A: (1982) Valoración de diferentes parámetros de normalidad mediante estudios con Tomografía Computarizada Cerebral. Rev. Dep. Psiquiatría Fac. Med. Barcelona. 9:335-350.

13. Guardia, J.: (1985) Estudio de un grupo de alcohólicos de larga evolución, con signos menores de encefalopatía. Rev. Dep. Psiquiatría Fac. Med. Barcelona. 12:331347.

14. Guardia Serecigni J; Prat Vigué G: (1997) Psicobiología del alcoholismo. Medicina del Trabajo 6:287-305.

15. Guardia Serecigni J; Prat Vigué G; Casas Brugué M: (1998) El sistema opioide como modulador del consumo de alcohol. Psiqquiatría Biológica 5:25-34.

16. Guardia J; Catafau AM; Batlle F; Martían JC; Segura L; Gonzalvo B; Prat G; Carrió I; Casas M: (2000) Stria- tal dopaminergic D2 receptor density measured by [123I] lodobenzamide SPECT in the prediction of treatment outcome of alcohool-dependent patients. AM. J. Psychiatry 157.

17. Guettat L; Guille M; Delbecq J; Depre A.: (1997) Folic acid deficiency with leukoencephalopathy and chronic axonal neuropathy of sensory predominance. Rev. Neurol. (Paris) 153:351-353.

18. Heinz A; Highley JD; Gorey JG; Saunders RC; Jones DW; Hommer D; Zajiecek K; Suomi SJ; Lesch KP; Weinberger DR; Linnoila M: (1998a) In vivo associatio between alcohol intoxication, agression and serotonin trasnporter abailability in nonhuman primates. Am. J. Psychiatry 155:1023-1028.

19. Heinz A; Ragan P; Jones DW; Hommer D; Williams W; Knable MB; Gorey JG; Doty L; Geyer C; Lee KS; Coppola R; Weinberger DR; Linnoila M: (1998b) Reduced central serotonin transporters in alcoholism. Am. J. Psychiatry 155:1544-1549.

20. Hietala J, West C, Syvälahti E, Nagren K, Lhikoinen P, Sonninen P, Ruotsalainen U: (1994) Striatal $D_{2}$ dopamine receptor binding characteristics in vivo in patients with alcohol dependence. Psychopharmacology; 116:285-290.

21. Holcomb HH; Cascella NG; Thaker GK; Medoff DR; Dannals RF; Tamminga CA: (1996) Functional sites neuroleptic drug action in the human brain: PET/FDG studies with and without haloperidol. Am. J. Psychiatry. 153:41-49.

22. Iwata N; Cowley DS; Radel M; Roy-Byrne PP; Goldman D: (1999) Relation between a GABA A $\alpha 6$ Pro385Ser substitution and benzodiazepine seusitivity. Am. J. Psychiatry 156:1447-1449.

23. Jenike MA; Rauch SL; Cummings JL; Savage CR; Goodman WK: (1996) Recent developments in neurobiology of absessive-compulsive disorder J. Clin. Psychiatry 57:492-503.

24. Johnson DL; Wiebe JS; Gold SM; Andreasen NC; Hichwa RD; Watkins GL; Ponto LLB: (1999) Cerebral blood flow and personality: a positron emission tomgrphy study. Am. J. Psychiatry 156:252-2576.

25. Kaplan HI; Sadock BJ; Grebb JA: Sinopsis de Psiquiatría. Séptima edición. Editorial Panamericana. Buenos Aires. 1996 (p. 118-128)

26. Kosten TR; Cheeves C; Palumbo J; Seibyl JP; Price LH; Woods SW: (1998)Regional cerebral blood flow during acute and chronic abstinence from combined cocaine-alcohol abuse. Drug and Alcohol Dependence 50 : 187-195.

27. Kung HF, Alavi A, Chang W, Kung M-P, Keyes JW Jr, Velchick MG, Billings J, Pan S, Noto R, Rausch A, Reilley J: (1990) In vivo SPECT imaging of CNS D-2 dopamine receptors: Initial studies with lodine-123IBZM in humans. J Nucl Med.; 31:573-579.

28. Laruelle M; Abi-Dargham A; van Dyck $\mathrm{CH}$; Rosenblatt W; Zea-Ponce Y; Zoghbi SS; Baldwin RM; Charney DS; Hoffer PB; Kung HF; Innis R: (1995) SPECT ima- 
ging of striatal dopamine release aftrer amphetamine challenge. J. Nucl. Med. 36:1182-1190.

29. Lingford-Hughes AR; Acton PD; Gacinovic S; Suckling J; Busatto GF; Boddington SJA; Bullmore E; Woodruff PW; Costa DC; Pillowsky LS; Ell PJ; Marshall EJ; Kerwin RW: (1998) Reduced levels of GABA-benzodiazepine receptor in alcohol dependencW in the asence of grey matter atrophy. Br. J. Psychiatry 173:116-122.

30. Litton Je; Neiman J; Pauli S, Farde L; Hindmarsh T; Halldin C, Sedvall G: (1993) PET analysis of [11 C] flumazenil binding to benzodiazepine receptors in chronic alcohol-depndent men and healthy controls. Psych. Res. 1-13.

31. Lomeña F; Catafau AM: (1995) SPECT cerebral. JANO 49:1634-1636.

32. Malison RT; Mc Dougle CJ; van Dyck $\mathbf{C H}$; Scahill L; Baldwin RM; Seibyl JP; Price LH; Leckman JF; Innis RB: (1995) [123I] ß-CIT SPECT Imaging of striatal dopamine transporter binding in Tourette's disorder. Am. J. Psichiatry 152:1359-1361.

33. Malison RT; Best SE; van Dyck CH; McCance EF, Wallace EA; Laruelle M; Baldwin RM; Seibyl JP; Price LH; Kosten TR; Innis RB: (1998) Elevated striatal dopamine transporters during acute cocaine abstinence as measured by [123I] $\beta$-CIT SPECT. Am. J. Psychiatry 155:832-834.

34. Matsuda K; Yamaji S; Ishii K; Sasaki M; Sakamoto S; Kitagaki H; Imamura T; Mori E.: (1997) Regional cerebral blood flow and oxygen metabolism in a patient with korsakoff syndrome. Ann. Nucl. Med. 11:33-35.

35. Mayberg HS; Liotti M; Brannan SK; McGinnis S; Mahurin RK; Jerabek PA; Silva JA; Tekell JL; Martin CC; Lancaster JL; Fox PT: (1999) Reciprocal limbic-cortical function and negative mood: converging PET findings in depression and normal sadness. Am. J. Psychiatry 156:675-682.

36. Miller RF; Harrison MJ; Hall-Craggs MA; Scaravilli F: (1998) Central pontine myelinolysis in AIDS. Acta Neuropathol. (Berl) 96:537-540.

37. Modell JG; Moutz JM: (1995) Focal cerebral blood flow change during craving for alcohol measured by SPECT. Journal of Neuropsychiatry and Clinical Neurosciences $7: 15-22$.

38. Neiman J: (1998) Alcohol as a risk factor for brain damage: neurologic aspects. Alcohol. Cli. Exp. Res. 22: 346S-351S.

39. Nicolás JM; Catafau AM; Estruch R; Lomeña FJ; Salamero M; Herranz R; Monforte R; Cardenal C; Urbano-Marquez A.: (1993) Regional cerebral blood flowSPECT in chronic alcoholism: relation to neuropsychological testing. J. Nucl. Medecine 34:1452-1459.

40. Salonen I; Hietala J; Laihinen A; Lehikoinen P; Leino L; Nagren K; Ruotsalainen U; Oikonen V; Tuokkola T; Näntö V: (1997) A PET study on the acute effect of ethanol on striatal D" dopamine receptors with [11C] raclopride in healthy males. Human pasychopharmacology 12: 145-152.

41. Saxena S; Brody AL; Schwartz JM; Baxter LR: (1998) Neuroimaging and frontal-subcortical circuitry in obsessive-compulsive disorder. Br. J. Psychiatry 173:(suppl 35), 26-37.

42. Schuckit MA; Smith TI: (1996) An 8-year follow-up of 450 sons of alcoholic and control subjects. Arch. Gen. Psychiatry 53:202-210.

43. Schuckit MA; Mazzanti C; Smith TI; Ahmed U; Radel M; Iwata N; Goldman D: (1999) Selective genotyping for the role o 5-HT2A, 5-HT2C, and GABA alpha 6 receptors and the serotonin transporter in the level of response to alcohol: a pilot study. Biol. Psychiatry 45:647-651.

44. Seibyl JP; Scanley E; Krystal JH; Innis RB: Neuroimaging methodologies. In: Charney DS; Nestler EJ; Bunney BS (Eds.) Neurobiology of mental illness. New York. Oxford University Press, 1999 (p. 170-189).

45. Seitz D; Widmann U; Seeger U; Nägele T; Klose U; Mann k, Grodd W.: (1999) Localized proton magnetic resonance spectroscopy of the cerebellum in detoxifying alcoholics. Alcoholism Clin. Exp. Res. 23:158163.

46. Smith KA; Morris JS; FristonKJ; Cowen PJ; Dolan RJ: (1999)Brain mechanisms associated with depressive relapse and associated cognitive impairment following acute tryptophan depletion. Br. J. Psychiatry 174:525529.

47. Stein EA; Pankiewicz J; Harsch HH; Cho JK; Fuller SA; Hoffmann RG; Hawkins M; Rao SM; Bandettini PA; Bloom AS.: (1998) Nicotine-induced limbic cortical activation in the human brain: a functinal MRI study. Am. J. Psychiatry 155:1009-1015.

48. Tiihonen J, Huikka J, Bergström K, Hakola P, Karhu J, Ryynänen OP, Föhr J: (1995) Altered striatal dopamine re-uptake site densities in habitually violent and nonviolent alcoholics. Nature Medicine 1:654-657.

49. Verhoeff NP, Kapucu O, Sokole-Busemann E, Van Royen EA, Janssen AG: (1993) Estimation of dopamine $D 2$ receptor binding potential in the striatum with iodine-123-IBZM SPECT: Technical and interobserver variability. J. Nucl. Med.34:2076-2084.

50. Volkow ND; Fowler JS; Wolf AP; Hitzemann R; Dewey S; Alpert R; Hoff A: (1991) Changes in brain glucose metabolism in cocine dependece and withdrawal. Am. J. Psychiatry 148:621-626.

51. Volkow ND; ; Fowler JS; Wang GJ; Hitzemann R; Logan J;Schlyer D; Dewey S; Wolf AP: (1993a) Decreased dopamine D2 receptor availability is associated with reduced frontal metabolism in cocaine abusers. Synapse 14: 169-177.

52. Volkow ND; Wang GJ; Hitzemann R; Fowler JS; Wolf AP; Pappas N; Bigeon A; Dewey SL: (1993b) Decreased cerebral response to inhibitory neurotransmission in alcoholics. Am. J. Psichiatry. 150:417-422.

53. Volkow ND; Wang GJ; Hitzemann R; Fowler JS; Overall JE; burr G; Wolf AP: (1994) Recovery of brain glu- 
cose metabolism in detoxified alcoholics. Am. J. Psychiatry 151:178-183.

54. Volkow ND; Wang GJ; Begleiter H; Hitzemann R; Pappas N; Burr G; Pascani K; Wong C; Fowler JS; Wolf A: (1995a) Regional brain metabolic response to lorazepam in subjects at risk for alcoholism. Alcoholism Clin. Exp. Res. 19:510-516.

55. Volkow ND; Ding YS; Fowler JS; Wang GJ; Logan J; Gatley JS; Dewey S; Ashby C; Liebermann J; Hitzemann R; Wolf AP: (1995b) Is Methylphenidate like cocaine? Am. J. Psychiatry 52: 456-463.

56. Volkow ND, Wang GJ, Fowler JS, Logan J, Hitzemann R, Ding YS, Pappas N, Shea C, Piscani K: (1996a) Decreases in dopamine receptors but not in dopamine transporters in alcoholics. Alcoholism: Clinical \& Experimental Research; 20:1594-1598

57. Volkow ND; Wang GJ; Fowler JS; Gatley SJ; Logan J; Dewey SL; Hitzemann R; Lieberman J: (1996b) Relationship between psychostimulant-induced "high" and dopamine transporter occupancy. Proc. Nat. Acad. Sci. USA 93: 10388-10392.

58. Volkow ND; Ding Y-S; Fowler JS; Wang GJ: (1996c) Cocaine addiction: hypothesis derived from imaging studies with PET. J. Addict. Dis 15:55-71.

59. Volkow ND; Wang GJ; Fowler JS; Hitzemann R; Pappas N; Pascani K; Wong C: (1997a) Gender differences in cerebellar metabolism: test-retest reproductibility. Am. J. Psychiatry 154: 119-121.
60. Volkow ND; Wang GJ; Fischman MW; Foltin RW; Fowler JS; Abumrad JS; Vitkun NN; Logan J; Gatley SJ; Pappas N; Hitzemann R; Shea K: (1997b) Relationship between subjective effects of cocaine and dopamine transporter occupancy. Nature 386: 827830.

61. Volkow Nd; Wang Gj; Overall Je; Hitzemann R; Fowler JS; Pappas N; Frecska E; Piscani K: (1997c) Regional brain metabolic response to lorazepam in alcoholics during early and late alcohol detoxification. Alcohol. Clin. Exp. Res. 21:1278-1284.

62. Volkow ND, Gur RC, Wang GJ, Fowler JS, Moberg PJ, Ding YS, Hitzemann R, Smith G, Logan J: (1998) Association between decline in brain dopamine activity with age and cognitive and motor impairment in healthy individuals. Am. J. Psychiatry; 155:344-349.

63. Volkow ND, Wang GJ, Fowler JS, Logan J; Gatley SJ; Gifford A; Hitzemann R; Ding YS; Pappas N: (1999a) Prediction of reinforcing responses to psychostimulants in humans by brain dopamine D2 receptors levels. Am. J. Psychiatry. 156:1440-1443.

64. Volkow ND, Wang GJ, Fowler JS, Hitzemann R, Angrist B; Gatley SJ; Logan J; Ding YS; Pappas N: (1999b) Association of methylphenidate-induced craving with changes in right striato-orbitofrontal metabolism in cocine abusers: implications in addiction. Am. J. Psychiatry 156:19-26. 
